\title{
CALCIFIED MESENTERIC LYMPHANGIOMA
}

BY

\author{
R. L. BISHTON, C. P. SAMES and HUGH R. E. WALLIS \\ From The Royal United Hospital and St. Martin's Hospital, Bath
}

(RECEIVED FOR PUBLICATION SEPTEMBER 2, 1957)

Levene, Walker and White (1956) reported two cases of mesenteric lymphangioma which presented as acute abdominal emergencies. They reviewed the published work, and showed that this is a rare condition. The following case is reported as an interesting complication of this disease.

\section{Case Report}

Paul R., aged 12, had from the age of 5 years recurrent attacks of central abdominal pain. These were accompanied by feelings of nausea and fullness in the epigastrium. The pain was colicky in nature, associated with constipation and relieved to some extent by the

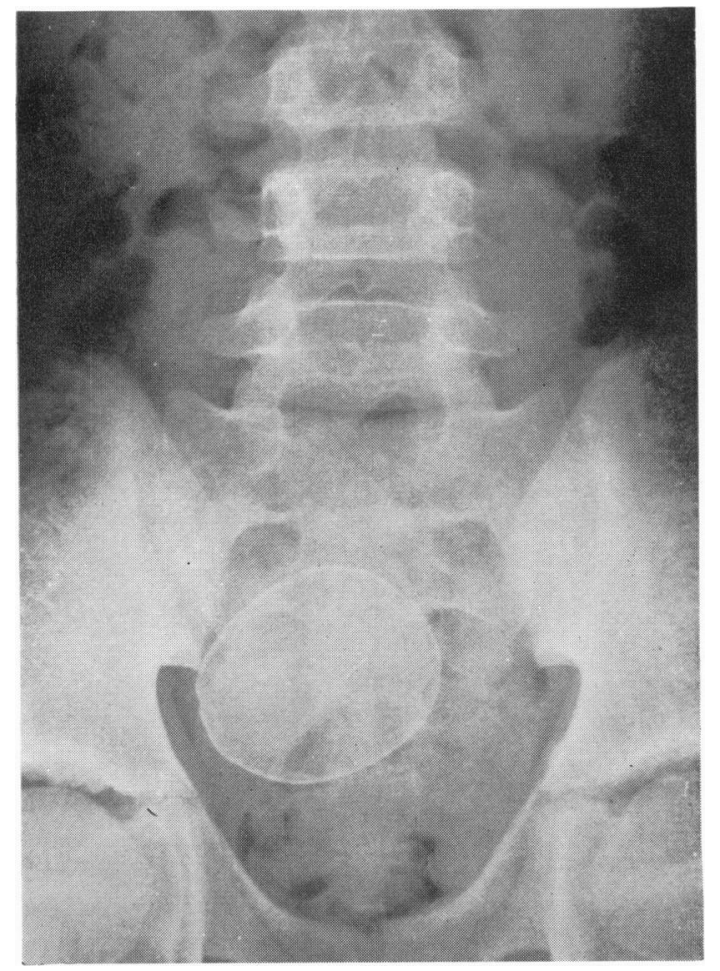

FIG. 1.-Radiograph of the pelvis.

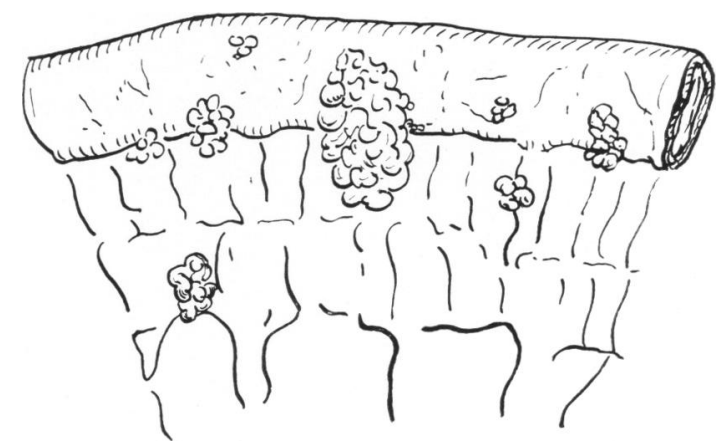

FIG. 2.-A portion of the jejunum seen at operation (about hal actual size).

passage of flatus. At first the attacks occurred at intervals of five or six weeks, and they lasted for 24 hours. By the time he was 12 they had become less frequent but more severe, and vomiting occurred.

On examination of the abdomen there was no physical abnormality, but rectal examination revealed a large, mobile, spherical mass which could be balloted in the abdomen. The blood picture and urine were normal. A tuberculin test was negative. A radiograph showed a calcified mass in the pelvis (Fig. 1). A barium enema revealed no communication with the large bowel.

Laparotomy was undertaken (C.P.S.), and there was found to be a little cloudy fluid in the peritoneal cavity. The surface of the jejunum and most of the ileum showed extensive engorgement of the lymphatics, which in many places had formed collections of lymphatic cysts (Fig. 2). At the distal end of the ileum there was a large, round, hard mass lying in the mesentery, but attached to the bowel wall (Fig. 3). The tumour was excised together with $4 \mathrm{~cm}$. of the ileum, and an end-to-end anastomosis was performed. In addition, a small nodule was taken from the mesentery for the purpose of histology. The patient made a good recovery. Three months later he was very well and had no abdominal pain or nausea.

\section{Pathology Report (R.L.B.)}

The mesenteric nodule was a fatty nodule $0.5 \mathrm{~cm}$. in diameter and consisted of fibro-fatty tissue in which were many dilated lymphatic spaces. No other lesion was seen 


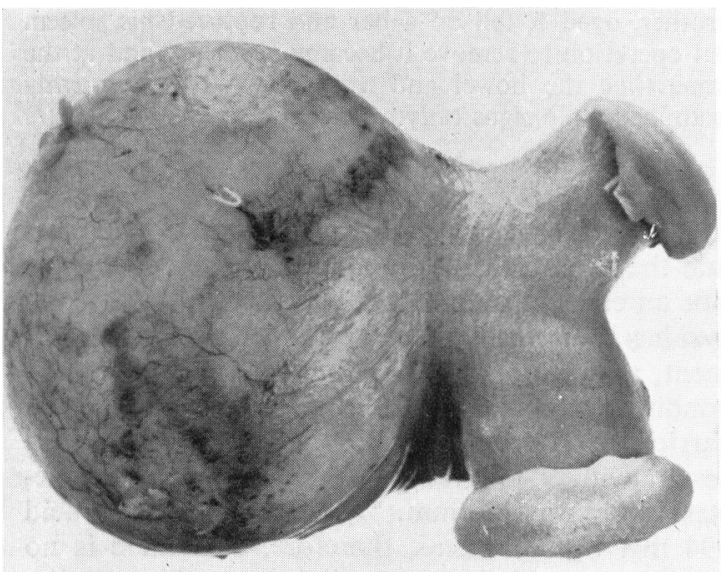

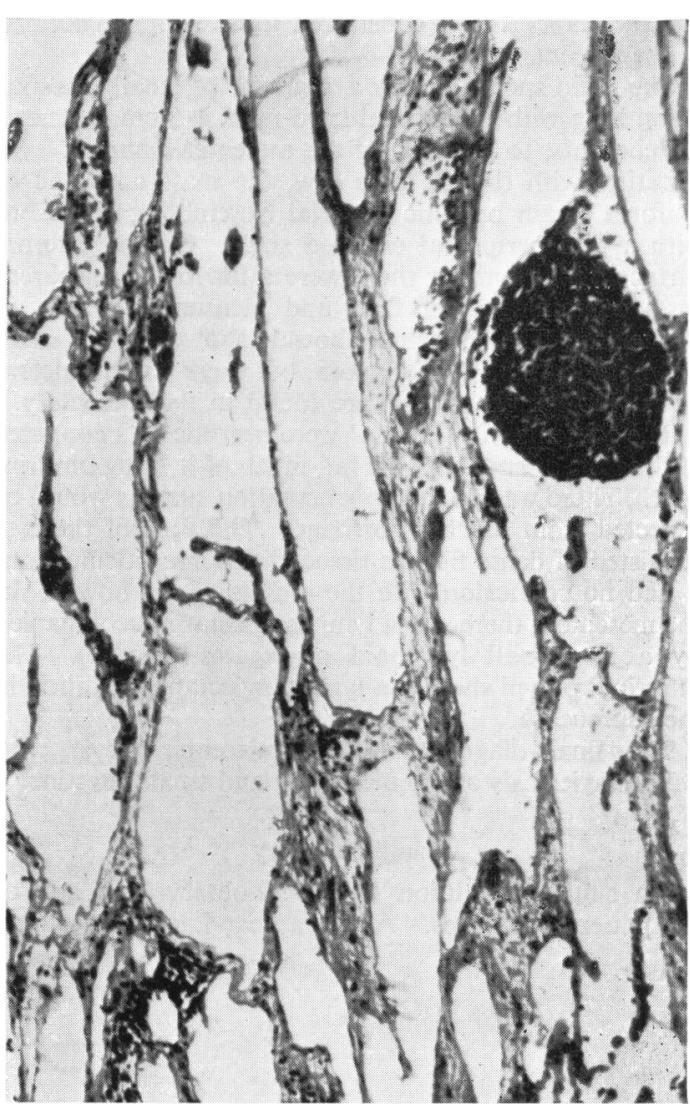

FIG. 4.-Section of mesentery showing lymphangiectasis with some lymphoid aggregates $(\times 120)$.

FIG. 3B.

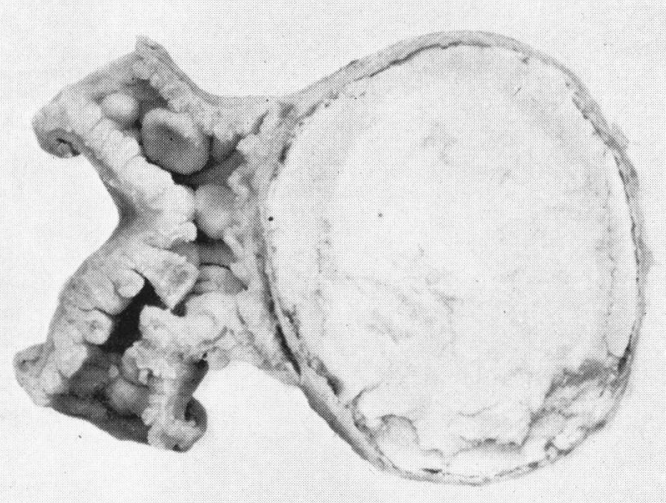

Fig. 3.-A and B: Cyst and attached bowel. C: Cut surface of specimen showing polypoidal mucosa of small bowel (actual size).

FIG. 3C. 
and the diagnosis was considered to be lymphangiectasis of the mesentery.

The main specimen was a segment of small intestine $4 \mathrm{~cm}$. long with a spherical hard mass $4.5 \mathrm{~cm}$. diameter attached just to one side of the mesenteric border. On bisection with the aid of a saw, the mass consisted of uniform cream necrotic material (resembling caseation) with a thin peripheral calcified shell. On the external surface of the tumour there were a few tiny transparent cysts containing clear fluid and measuring $1 \mathrm{~mm}$. in diameter. The attached bowel showed two small polypoid lesions of the mucosa, but there was no ulceration. No lymph nodes were found in the mesentery.

The contents of the 'cyst' were necrotic and consisted of droplets of sudanophilic fat, much of it being birefringent. There was no iron pigmentation such as would be expected from old haemorrhage. The wall of the cyst consisted of dense fibrous tissue with some calcification; it had no connexion with the muscle of the bowel. In the mesentery there was a lymphangiectasis accompanied by a few small lymphoid aggregates (Fig. 4). The intestinal polypi showed a lymphangiectatic condition in the submucosa.

The final diagnosis was of mesenteric cyst with lymphangiectasis of the mesentery and small intestine.

\section{Family History}

No similar condition has been observed in any of the patient's relatives. About a year later his younger brother, aged 7, fell on a bar and ruptured his spleen. An operation to remove it became necessary and at the same time the bowel and mesentery were thoroughly examined. No signs of lymphangiectasis were seen.

\section{Discussion}

The nature of the attacks, the feeling of fullness and the relief from passing flatus, suggest that there was an element of subacute obstruction. Since the cyst has been removed there has been much improvement, and there are no symptoms referable to the condition. As a matter of interest a fat balance was carried out after the operation. This gave a normal result, with $91.5 \%$ absorption. The blood cholesterol level was $150 \mathrm{~mm}$. \%, and the total fatty acid $194 \mathrm{mg}$. \%. It seems, therefore, that there is no interference with fat absorption.

This appears to be the first case recorded of calcification in a lymphangiectatic cyst.

We wish to thank Dr. K. Reeves, who referred the case, Mr. T. Schofield, F.R.C.S., for information about the patient's brother, Mr. N. Swain for the print of the radiograph and Mr. G. W. Griffin, F.I.M.L.T., for the photomicrograph.

REFERENCE

Levene, M., Walker, P. A. and White, T. A. (1956). Arch. Dis. 